Research Article

\title{
Research on the Supply Chain Performance Evaluation Mechanism Based on Emergencies
}

\author{
Wenxue Ran ${ }^{D},{ }^{1}$ Yimin $H u\left(\mathbb{D},{ }^{2}\right.$ and Huasen $F^{3}$ \\ ${ }^{1}$ Department of Logistics School, Yunnan University of Finance and Economics, Kunming, Yunnan, China \\ ${ }^{2}$ Department of Logistics School, Postgraduate of Logistics Engineering, Yunnan University of Finance and Economics, Kunming, \\ Yunnan, China \\ ${ }^{3}$ Hubei Province Tobacco Company Yichang City Company, Yichang, Hubei, China \\ Correspondence should be addressed to Yimin Hu; huyimin1998@163.com
}

Received 3 August 2021; Revised 19 October 2021; Accepted 28 October 2021; Published 7 December 2021

Academic Editor: Ya Jia

Copyright (c) 2021 Wenxue Ran et al. This is an open access article distributed under the Creative Commons Attribution License, which permits unrestricted use, distribution, and reproduction in any medium, provided the original work is properly cited.

\begin{abstract}
Some emergencies have produced enormous changes in market demand in recent years as the economy has progressed. The supply chain's capacity to adapt to this market demand has a substantial impact on the company's future growth. As the frequency of emergencies rises, emergency management is becoming increasingly critical for enterprises. This article examines the responsiveness and profit status of the supply chain under the three conditions of total complete information symmetry, incomplete information symmetry, and information asymmetry based on the information sharing degree of supply chain firms. The research offers a novel approach to emergency management. It makes recommendations for how the company may share information to improve its emergency management capabilities. Finally, the feasibility of the model is verified and analyzed by a case.
\end{abstract}

\section{Research Background and Research Significance}

1.1. Research Background. The concept of the supply chain was put forward in 1960, but its implementation in China started relatively late. After China entered the reform and opening-up policy in 1978, economic development and technological innovation continued to advance. However, with the development of the global internet economy, various emergencies have also increased the risks faced by enterprises [1]. During the Spring Festival of 2020, the sudden COVID-19 epidemic has brought enormous challenges to all walks of life. And the challenges faced by enterprises in emergency management have continued to this day [2].

During the epidemic, SMEs (small- and medium-sized enterprises) are more vulnerable to emergencies due to a lack of resources [3]. As a result, some of these companies were forced to close their doors, lay off employees, or even go bankrupt. For logistics companies, fixed assets account for a relatively high proportion. The supply chain becomes disconnected with stringent municipal blockades, transportation disruptions, and plant shutdowns [4]. All these will lead to a substantial increase in the overall operating costs of supply chain companies and cause tremendous losses to the company.

The occurrence of emergencies has intensified the speed of corporate management and technological change. For example, faced the challenges of COVID-19, some companies quickly came up with countermeasures, such as zerocontact takeout, zero-contact delivery of emergency supplies, and strict epidemic prevention and control. Companies that take measures first will reduce losses, sufficient to prepare for the later resumption of work and production in advance. The response ability of a company to emergencies will be a crucial breakthrough in the company's future development. Therefore, supply chain management (SCM) under an emergency (such as earthquakes, mountain torrents, fires, mudslides, and epidemics) has entered people's field of vision.

In recent years, due to the uncertainty of demand and the volatility of the business environment, the supply chain was 
facing increasingly fierce competition, but with strong economic and technical support, the exploration of SCM is also gradually improving and ameliorates. For enterprises, the emergency is both an opportunity and a challenge [5]. As far as the current market is concerned, companies will retreat if they do not advance. Both technological innovations and management advancements play a vital role in the further development of companies. In addition, concepts and technologies such as artificial intelligence, the Internet of Things, big data, cloud services, and block chain have emerged and are applied in various industries. The era of big data is opening up new possibilities for emergency management [6].

Nevertheless, improving the overall performance enhancement of the supply chain organization needs evaluation [7]. Managing supply chain performance (SCP) is critical for improving customer experience and retention, lowering costs, and gaining market share through faster product innovation [8]. In addition, while a firm's response is affected by supply chain coordination, it must respond quickly to specific markets brought about by unexpected events to ensure its long-term viability. Therefore, how to effectively deal with all kinds of unconventional emergencies and improve the emergency management ability of enterprises to deal with this emergency is arousing widespread concern from all walks of life [9].

The ultimate goal of SCM under emergencies is to increase the total profit of the supply chain. Evaluating the performance of supply chain companies in emergencies is of great significance for improving supply chain surplus [10]. However, the emergency supply chain involves many management elements, and the traditional qualitative analysis and comprehensive evaluation methods are insufficient in practice [11]. The authors use rough sets to filter the indicators, eliminate redundant targets, and simplify many indicators for evaluating emergency supply chain systems into a few core indicators. Therefore, multiindicator supply chain performance evaluation (SCPE) will be more comprehensive and reliable under normal circumstances, but the multiple indexes in emergency situations will bring some difficulties and challenges. For example, indicators used for evaluation often lack sufficient information to support [12].

In general, postemergency evaluations may only give a limited amount of data, such as the number of victims and the amount of money lost, as well as the locations affected [13]. In addition, the evaluation of many vital indicators is too subjective, and the targets may not necessarily reflect the company's operating performance [14]. More importantly, complex information systems are difficult to model and expensive to build [15]. In indicators, combing the previous studies found that reactivity is one of the first-level significant indicators. Chen et al. [16], for example, evaluated the assessment indicators of emergency rescue capacities during large epidemics and discovered that emergency response capabilities weighted 0.53 in the three first-level targets. In addition, Larsson et al. [17] proposed the cost/benefit estimate. It can be used as a backup strategy if the emergency information is insufficient.
This paper does not provide too many redundant indicators while summarizing the above research experience. Abandon previous multi-index evaluation, and only consider the supply chain's responsiveness and profit in emergencies. Based on the enterprise's response to the emergency, to analyze the total profit of the supply chain in the case of complete information symmetry, incomplete information symmetry, and information asymmetry, study how companies can better manage emergencies and increase the total profit of the supply chain.

1.2. Research Significance. At present, disasters worldwide have become more frequent and diverse, and large-scale emergencies are pushing the global supply chain to the brink of collapse [18, 19]. In particular, the speed of market changes is gradually accelerating, and companies are confronting tremendous pressure on sustainable development and SCM [20]. The purpose of SCM is to reduce production risks and production costs and increase total revenue [21]. Therefore, evaluating the performance of the supply chain in emergency situations is of practical significance to the development of today's enterprises. This article will provide an idea for SCPE in an emergency. The research results have important theoretical significance for the development of enterprises in emergencies.

There are five parts to this paper. The second part is to sort out the current situation of the development of SCPE in emergency situations. The third section is to model the performance evaluation of the supply chain and compare the modeling results under the three information modes. The fourth part is a numerical example to verify the model. Finally, it is the suggestions for improving the ability of enterprises to respond to emergencies and a summary of this article.

\section{Literature Review}

In China, the occurrences of SARS in 2003, H1N1 influenza in 2009, H7N9 avian influenza in 2013, COVID-19 in 2019, and other public health catastrophes had a significant impact on the country's politics, economics, commerce, and population's health [22]. Social unrest, natural catastrophes, and emergencies have all occurred regularly in recent years. Emergency management (EM) systems are critical for preserving lives and minimizing property damage [23]. This section covers two elements of SCPE in emergency situations: indicator selection and research methodologies.

2.1. Index Selection. Considering that the SCPE under emergencies will be affected by many factors, it is difficult to consider all indicators when the amount of information is limited. The most direct method is to optimize the vital indicators for evaluation. In selecting key indicators, the subjectivity of experts may complicate the problem, leading to a lack of information and ambiguity. For this reason, Chen and Song [24] proposed a TOPSIS method based on hesitant and ambiguous information to solve the above issues. In addition, Zhou et al. [25] also proposed to combine 
D-number theory with decision-making experiment and evaluation laboratory (DEMATEL), which is D-DEMATEL, used to identify critical success factors (CSFs) for EM. However, the proposed method is more suitable for identifying CSF in emergency management that inherently has a language assessment process.

Liu et al. [26] proposed a comprehensive method based on the fuzzy cognitive map (FCM) and Pearson productmoment correlation coefficient to determine the significant risk factors in EM and finally ensured five key targets: emergency system, organizational structure, sense of responsibility, and demand evaluation and information submission procedures. Li et al. [27] proposed to switch the evaluation of influencing factors in the form of intuitionistic fuzzy numbers (IFNs) into basic probability assignment (BPA). Then, the Dempster-Shafer theory is used to combine group decision-making. By doing this, there is no need for fuzzification of the interferon. DEMATEL is applied to each fused BPA, seeking the final result from different aspects. Finally, five key elements are determined: organizational structure and sense of responsibility, simulated disaster drills, unified government leadership and coordination, information submission procedures, and modern logistics technology applications. Ding and Liu [28] proposed a new combination method based on two-dimensional uncertain linguistic variables (2DULVs) and DEMATEL and finally determined five key indicators: emergency system, emergency plan, logistics center financial security, unified government leadership and coordination, and effective emergency information system. The five target indicators studied above all have information submission procedures in common, and these common points are all conducive to performance evaluation after emergencies. Other indicators are more appropriate for preemergency preparedness.

Sahinoz et al. [29] found a significant positive correlation between all CSFs, plans, response and recovery criteria, and performance differences. A review of previous studies found that information collected in the early stage will affect performance evaluation in the later stage. Generally speaking, there is a positive correlation between information, response, and performance evaluation. Based on collating the literature and considering the difficulty of information collection under actual conditions, this paper uses response ability as an independent variable in the model. And research will adopt economic indicators to evaluate SCP under emergencies. The modeling results will discuss the total profit of supply chain companies under three different information modes.

2.2. Research Methodologies. According to statistics, China's annual direct economic losses caused by natural disasters exceed 100 billion, with 1 million casualties [30]. Therefore, strengthening the management of emergencies has important practical significance. In the event of an emergency, establishing an evaluation system for businesses may help uncover management flaws and enhance the ability of enterprises to respond [31]. However, combing through previous studies found that the difficulty of emergency evaluation lies in quantification and value standardization, which leads to the need to combine quantitative and qualitative evaluation methods [32]. This section will sort out the development status and usual research methods of supply chain emergency assessment.

First of all, due to the complexity, variability, and suddenness of emergencies, dynamic development needs to be followed up at any time. EM needs to change over time. Aiming at the variational value of information, the authors have developed a multistage information quantitative dynamic evaluation model [33]. In addition, unconventional emergencies are difficult to predict and control. The emergency logistics SC faces huge natural risks in operation and is prone to chain disconnection. Ge et al. [34] proposed eight strategies to establish and develop fuzzy topic methods to enhance the flexibility of the emergency logistics SC. Duong and Chong [35] studied 157 papers and answered how to help the supply chain cope with and recover from interruptions.

Usual evaluation methods are analyzed as follows. A balanced scorecard needs to capture a lot of very different data. However, due to the lack of a large amount of performance evaluation data, the balanced scorecard implementation in areas such as healthcare has been hampered [36]. The challenge also includes the evaluation of SCP after an emergency. Zhang and Fu [37] integrated the data envelopment analysis (DEA) and analytic hierarchy process (AHP) algorithms. The model eliminated not only the subjectivity of the AHP but also the DEA dichotomy. The research results show that the evaluation method can measure the performance of emergency logistics more efficiently and feasibly. However, to overcome the weakness of the traditional AHP, Deng et al. [38] used triangular fuzzy numbers to develop a new performance evaluation method-triangular fuzzy analytic hierarchy process (TFAHP). In addition, given the ambiguity characteristics in the judgment of decision makers, Bangwang [39] proposed the hierarchy process of triangular fuzzy numbers and fuzzy linguistic variables and applied it to the performance evaluation of emergency logistics outsourcing suppliers. Aiming at the emergency coordination problem of supply chain outsourcing risk with all fuzzy uncertainties and random uncertainties, Zhang et al. [40] proposed an algorithm to solve the design model of the three-stage supply chain example. This research solves the ambiguity and randomness but applies to the coordination problem in emergencies.

Scenario-based models can reproduce the development process of emergencies and find out the key factors that can effectively reduce the loss in an emergency to make practical recommendations [41]. However, such methods are suitable for predictable and repeatable events, such as earthquakes and mudslides. Zhang et al. [42] used the COVID-19 regional emergency logistics capability as the study object and developed a BP neural network-based evaluation model for emergency logistics capability. Finally, the COVID-19 event validates the scientificity and feasibility of the assessment model, but the BP neural network is more suitable for model solving with multiobjective input. Aiming at problems such 
as insufficient risk identification, incomplete and inaccurate data, and decision maker has different preferences, Bing and Weimin [43] combined soft set theory with classical fuzzy rough set theory to establish a new emergency plan evaluation model, but this model also tends to be evaluated before emergencies.

Based on the combing and analysis of the previous studies, usual performance evaluation methods have certain limitations in performance evaluation after emergencies. Data modeling is the most basic analysis method, but it is also the most direct. In this paper, after mathematical modeling of response capability, the DEA algorithm is used to solve it. The evaluation results of the total profit of the supply chain under three different information modes will have guiding significance for improving the level of EM of enterprises.

\section{Establish a Model for Evaluating Supply Chain Performance under Emergencies}

This section will establish an emergency SCPE model based on the company's ability to respond to emergencies. According to an investigation by Raweewan and Ferrell [44], the success rate of supply chain collaboration is only $20 \%$. The root cause of failure lies in information sharing. The total profit of supply chain enterprises under different information sharing modes of enterprises is analyzed. The relationship between the company's response ability to emergencies, information sharing, and profit is studied, and the performance of the supply chain is evaluated. For the convenience of readers, the main variable assumptions of the article are shown in Table 1.

3.1. Formulation of the Basic Model. This article utilizes a model research object of a brief secondary supply chain of a manufacturer and a shop to conduct research and analysis on the ability of the chain to respond to market demand before and after emergencies, as well as the profit under each situation. Companies may arrange data and statistical analysis in combination with today's information technology to create certain forecasts on market demand under normal circumstances, even if market demand is unclear. Manufacturers will establish their response based on the market demand forecast. Capability is $R$, the cost of the manufacturer's construction response capability needs $C_{R}$, and the production cost required to produce each unit of the product is $c$. After the retailer observes the market demand, it will place a production order to the manufacturer. The manufacturer will arrange a production plan for it and deliver the goods to the retailer at the predetermined time. Finally, the retailer sells to the market at the market price of $p$.

When the market changes, both producers and retailers will forecast market demand $D=d+\varepsilon$, where $d$ is a constant, $\varepsilon$ obeys $\mu=0$, the probability density is $f(\bullet)$ (continuously differentiable), and the distribution is $F(\bullet)$ (random distribution). When the responsiveness is $R$, let $E$ $[\min (D, R)]=E[\min (d, R)]$ be the projected sales volume (assuming unsold inventory is zero). The profit function under the supply chain model is

$$
P^{s}(R)=(p-c) E[\min (d+\varepsilon, R)]-C_{R} R
$$

The profit function of the supply chain is an increasing concave function. The first-order derivation of (1) makes it zero to obtain the optimal response capacity $R^{*}=d+F^{-1}\left(p-C-C_{R} / p-C\right)$.

According to the wholesale price model of the traditional supply chain (assuming the traditional wholesale price is $p^{\prime}$ ), the profit functions of manufacturers and retailers are

$$
\begin{aligned}
& P^{m}(R)=\left(p^{\prime}-c\right) E[\min (d+\varepsilon, R)]-C_{R} R, \\
& P^{r}(R)=\left(p-p^{\prime}\right) E[\min (d+\varepsilon, R)] .
\end{aligned}
$$

Solving equations (2) and (3), the response capability under the traditional wholesale model can be obtained as

$$
R^{\prime}=d+F^{-1}\left(\frac{p^{\prime}-C-C_{R}}{p^{\prime}-c}\right) .
$$

Among them, $R^{\prime}<R^{*}$; that is, the ability of enterprises under the supply chain model to respond to market demand is better than that of enterprises under the traditional wholesale model. The following will study the supply chain responsiveness mechanism in different situations.

3.2. Research on the Mechanism of Response Ability in Emergencies. Attributes of suppliers such as capabilities are considered important aspects of successful buyer-supplier relationships [45]. Generally speaking, the enterprise in the supply chain is usually the retailer who makes an appointment payment $p^{\prime \prime}$ for the manufacturer's production capacity to coordinate the response capacity. It increases capital chain circulation, making the supply chain more flexible to changes in market demand and allowing items that match the market need to be swiftly put on the market at the right moment. After a sudden market demand occurs, the retailer makes an appointment with the manufacturer for response capability $R$ and pays $p^{\prime \prime}$ to the manufacturer for production. The profit functions of the retailer making an appointment with the manufacturer are

$$
\begin{aligned}
P^{m}(R) & =\left(p^{\prime}-c\right) E[\min (d+\varepsilon, R)]-C_{R} R+p^{\prime \prime} R, \\
P^{r}(R) & =\left(p-p^{\prime}\right) E[\min (d+\varepsilon, R)]-p^{\prime \prime} R .
\end{aligned}
$$

It is possible to get equations (5) and (6) when $p^{\prime \prime}=\left(p-p^{\prime}\right) C_{R} /(p-c)$, the supply chain's responsiveness, is coordinated by setting up an appointment with the manufacturer's production capacity. Second, the supply chain profit will be divided into two parts: one will go to the producer, with a proportion as $\tau=\left(p^{\prime}-c\right) /(p-c) * 100 \%$, and the other will go to the retailer, with a ratio of $1-\tau$. The appointment of production capacity will strengthen the relationship between retailers and suppliers, but this is a response capacity model with symmetrical information. 
TABLE 1: Introducing the main symbols.

\begin{tabular}{|c|c|}
\hline$R$ & Response ability (variable) \\
\hline$C$ & Production cost per unit \\
\hline$p$ & Market price \\
\hline$D=d+\varepsilon$ & Market demand ( $d$ is a constant and $\varepsilon$ is a random distribution) \\
\hline$C_{R}$ & Manufacturer's response cost \\
\hline$E[\min (D, R)]$ & Expected sales \\
\hline$P^{s}(R)$ & Total profit of the supply chain \\
\hline$R^{*}$ & Optimal responsiveness \\
\hline$R^{\prime}$ & Traditional optimal responsiveness \\
\hline$P^{m}(R)$ & Manufacturer profit function \\
\hline$P^{r}(R)$ & Retailer profit function \\
\hline$p^{\prime}$ & Traditional wholesale price \\
\hline$p^{\prime \prime}$ & Pay by appointment \\
\hline$\tau$ & $\%$ of manufacturer's profit \\
\hline $1-\tau$ & $\%$ of retailer's profit \\
\hline$D+D^{\prime}=d+\varepsilon+v+\xi$ & Sudden total market demand ( $d, \varepsilon, v$, and $\xi$ need specific information mode definition) \\
\hline$P^{s 1}(R)$ & The supply chain \\
\hline$P^{m 1}(R)$ & Profit function under emergencies \\
\hline$P^{r 1}(R)$ & Retailer \\
\hline$\lambda$ & Additional production cost \\
\hline$R_{s 1}$ & Complete information symmetry \\
\hline$R_{s 2}$ & Incomplete information symmetry \\
\hline$R_{s 3}$ & Information asymmetry \\
\hline
\end{tabular}

First and foremost, in the event of an emergency, the decision maker has the fundamental reaction capability $R$, while the market need is $D=d+\varepsilon$. The advent of an emergency creates new demand to the market. The new market demand is considered to be separate from the original market demand and to be a mixture of two demand components: $D^{\prime}=v+\xi\left(D^{\prime}>0\right)$. Then, the total need under the emergency is $D+D^{\prime}=d+\varepsilon+v+\xi$. Secondly, the performance of SCM can be enhanced by implementing information sharing and coordination [46, 47]. Then, according to different levels of information sharing between companies in the supply chain, the ability to respond to sudden market demand in the supply chain will be divided into three situations: complete information symmetry, incomplete information symmetry, and information asymmetry mechanism for research.

Among them, complete information symmetry means that retailers and manufacturers share all market demand information. Incomplete information symmetry refers to that only part of the market demand information is shared. Information asymmetry means that all market demand information is not shared. The specific manifestation in the function will be given in detail later. After the sudden market demand occurs, the retailer makes an appointment with the manufacturer for production capacity, and the profit functions of the supply chain, the manufacturer, and the retailer are

$$
\begin{aligned}
P^{s 1}(R) & =(p-c) E[\min (d+\varepsilon+v+\xi, R)]-C_{R} R-\lambda\left(R-R^{*}\right), \\
P^{m 1}(R) & =\left(p^{\prime}-c\right) E[\min (d+\varepsilon+v+\xi, R)]-C_{R} R+p^{\prime \prime} R-\lambda\left(R-R^{*}\right), \\
P^{r 1}(R) & =\left(p-p^{\prime}\right) E[\min (d+\varepsilon+v+\xi, R)]-p^{\prime \prime} R .
\end{aligned}
$$

$R$ stands for the sudden demand reaction capability, $R *$ stands for the optimal response capability under ordinary market conditions, and $\lambda$ is the additional cost of enhanced response capability for unexpected demand.

3.2.1. Research on the Mechanism of Response Ability under Complete Symmetry of Information. The response ability under absolute knowledge symmetry is in which the retailer and the manufacturer have equal knowledge of the sudden market demand. There is no private information for one side, i.e., all of $v$ and $\xi$ are shared. The ability to set an appointment is linear in this instance, $d, v$, and $\xi$ are constants, and $\varepsilon$ is the only random variable. $P^{s 1}(R)$ is a strictly concave function among them; therefore, it may be derived by taking the first derivative and setting it to zero:

$$
R_{s 1}=d+v+\xi+F^{-1}\left(\frac{p-c-C_{R}-\lambda}{p-c}\right) \text {. }
$$

Then,

$$
v+\xi>F^{-1}\left(\frac{p-c-C_{R}}{p-c}\right)-F^{-1}\left(\frac{p-c-C_{R}-\lambda}{p-c}\right) .
$$


$F^{-1}\left(\left(p-c-C_{R}\right) / p-c\right)$ is the market demand variable under normal conditions, and $F^{-1}\left(\left(p-c-C_{R}-\lambda\right) / p-c\right)$ is the market demand variable under emergency conditions. Formula (9) means that the reaction capability can be changed only when the emergency demand $v+\xi$ is larger than the market demand change. Otherwise, the original reaction capabilities, as well as the previous output, will be retained. That is because the value of information will be negative if demand follows a random walk, and the value delivered is less than the expense [48]. To summarize, when the knowledge about a sudden market demand is entirely symmetrical, the supply chain's best response capability is

$$
R= \begin{cases}R_{s 1}, & v+\xi>F^{-1}\left(\frac{p-c-C_{R}}{p-c}\right)-F^{-1}\left(\frac{p-c-C_{R}-\lambda}{p-c}\right), \\ R^{*}, & \text { otherwise, }\end{cases}
$$

where

$$
R_{s 1}=d+v+\xi+F^{-1}\left(\frac{p-c-C_{R}-\lambda}{p-c}\right) .
$$

In addition, the supply chain can be coordinated from $p^{\prime \prime}$ to $\overline{p^{\prime \prime}}=\left(p-p^{\prime}\right)\left(C_{R}+\lambda\right) /(p-c)$ by adjusting the payment reservation capacity when the information in an emergency is fully symmetrical. At this point, the profit obtained by the manufacturer is $\tau+\eta$, where $\eta=\left(p-p^{\prime}\right) \lambda R^{*} /(p-c)$, while the profit obtained by the retailer is $1-\tau-\eta$.

3.2.2. Research on the Mechanism of Response Ability under Incomplete Information Symmetry. It hypothesized that the market demand information under the emergency is incomplete information symmetry for both manufacturers and retailers, i.e., manufacturers and retailers have the same degree of understanding of the two kinds of sudden market demand information: $v$ is a known constant, $\xi$ is subject to $\mu=0$, probability density $\mathrm{g}(\bullet)$, and distribution $\mathrm{G}(\bullet)$, namely, in the total market demand, $d$ and $v$ are constants, $\varepsilon$ and $\xi$ are random variables, and $P^{s 1}(R)$ is a strictly concave function, assuming that the first derivative of $P^{s 1}(R)$ is zero:

$$
R_{s 2}=d+v+(F \cdot G)^{-1}\left(\frac{p-c-C_{R}-\lambda}{p-c}\right)
$$

only when

$$
v>F^{-1}\left(\frac{p-c-C_{R}}{p-c}\right)-(F \cdot G)^{-1}\left(\frac{p-c-C_{R}-\lambda}{p-c}\right) .
$$

The market reaction ability can be altered when the sudden market demand $v$ is larger than the difference between the market demand variables, same as equation (9). In summary, the supply chain's best emergency reaction capability with partial information symmetry is
$R= \begin{cases}R_{s 2}, & v>F^{-1}\left(\frac{p-c-C_{R}}{p-c}\right)-(F \cdot G)^{-1}\left(\frac{p-c-C_{R}-\lambda}{p-c}\right), \\ R^{*}, & \text { otherwise, }\end{cases}$

where

$$
R_{s 2}=d+v+(F \cdot G)^{-1}\left(\frac{p-c-C_{R}-\lambda}{p-c}\right) .
$$

At the same time, regardless of whether the information is entirely symmetrical or not, the percentage of profits of the companies at all stages of the supply chain changes the same, i.e., the total profit of the manufacturer is $\tau+\eta$, and the total profit of the retailer is $1-\tau-\eta$.

To sum up, by comparing the profit of the supply chain under the completely symmetric information model before and after emergencies, which can be known if the information of retailers and manufacturers is at the same level, the production capacity reservation mechanism is still effective. When $R>R^{*}$, however, the manufacturer will optimize its production capacity if it is not possible to schedule a coordination appointment. That is, the manufacturer's response ability is $R_{s 2}^{\prime}$ when used the traditional wholesale price. The results will be used in the following study.

$$
R_{s 2}^{\prime}=d+v+(F \cdot G)^{-1}\left(\frac{p^{\prime}-c-C_{R}-\lambda}{p^{\prime}-c}\right) .
$$

3.2.3. Research on the Mechanism of Response Ability under Information Asymmetry. The retailer's profit is monotonically increasing concerning the manufacturer's production capacity by observing formula (3). It means that when an emergency occurs under information asymmetric, the retailer will have the incentive to exaggerate market demand information and seek higher profits. During emergencies, exposure of the false information can increase supply chain's vulnerability [49]. It is because information sharing allows manufacturers' wholesale prices to respond to market demand. If the manufacturer is efficient in reducing costs, it will benefit the supply chain. Otherwise, it will damage the supply chain [50]. So, manufacturers can also decide whether to obtain demand information at a cost [51, 52].

Generally speaking, manufacturers will make two judgments to their production capacity when an emergency occurs. For the first time, they will make a judgment based on the emergency market demand information. For the second time, they will make a judgment based on the information provided by the retailer and then adjust their production capacity from $R$ to $R^{\prime}$ ( $R^{\prime}$ is the response ability of the supply chain to the traditional wholesale price under asymmetric information):

$$
R^{\prime}=d+v+(F \cdot G)^{-1}\left(\frac{p^{\prime}-c-C_{R}-\lambda}{p^{\prime}-c}\right) .
$$


Same as equation (16), the result does not include the random variable $\xi$ of market demand information under emergencies. Therefore, the supply chain response capability of the traditional wholesale price model is the same as that of the conventional wholesale price model when the information of sudden market demand is not fully symmetric. The classical game theory models are applied to the supply chain scheme to calculate the indicators used for evaluation [52]. Furthermore, Lima-Junior and Carpinetti [53] reviewed 84 SCPE studies since 1995 and found that AHP and DEA are the most commonly used technologies. In summary, this article will use game theory to study retailers' exaggeration behavior, and the calculation part will use DEA.

Based on the game method, the decision sequence of the manufacturer and the retailer is as follows: (1) the manufacturer will notify the retailer in advance of the scheduled capacity information, $\left\{R(\xi), p^{\prime}(\xi)\right\},(\xi \in[a, b])$, which is the manufacturer's capacity and cost adjustment based on the grasp of the sudden market demand. (2) The retailer issues a production order $\left\{R(\bar{\xi}), p^{\prime}(\bar{\xi})\right\}$ to the manufacturer after statistical analysis of the sudden market demand. Among them, $\bar{\xi}$ is the production order demand information reported by the retailer to the manufacturer, which is not equivalent to the authentic market demand information $(\xi)$ because of, perhaps, mixing with exaggerated components. (3) The manufacturer establishes a response ability $R(\bar{\xi})$ after receiving the order to carry out production. (4) The retailer receives it and sells it at the price of $p$.

Under the information asymmetry of sudden market demand, the profit functions of the supply chain, manufacturer, and retailer after capacity reservation are

$$
\begin{aligned}
\overline{P^{s 1}}(R(\bar{\xi}), \xi) & =(p-c) E[\min (d+\varepsilon+v+\xi, R(\bar{\xi}))]-C_{R} R(\bar{\xi})-\lambda\left(R(\bar{\xi})-R^{*}\right), \\
\overline{P^{m 1}}\left(R(\bar{\xi}), p^{\prime}(\bar{\xi}), \xi\right) & =\left(p^{\prime}-c\right) E[\min (d+\varepsilon+v+\xi, R(\bar{\xi}))]-C_{R} R(\bar{\xi})+p^{\prime}(\bar{\xi})-\lambda\left(R(\bar{\xi})-R^{*}\right), \\
\overline{P^{r 1}}\left(R(\bar{\xi}), p^{\prime}(\bar{\xi}), \xi\right) & =\left(p-p^{\prime}\right) E[\min (d+\varepsilon+v+\xi, R(\bar{\xi}))]-p^{\prime}(\bar{\xi}) .
\end{aligned}
$$

Manufacturers want retailers to provide authentic market demand information $(Q)$ to maximize their expected profits. Then,

$$
\begin{array}{ll}
\max & E \overline{P^{m 1}}\left(R(\bar{\xi}), p^{\prime}(\bar{\xi}), \xi\right), \\
& (1) \overline{P^{r 1}}\left(R(\xi), p^{\prime}(\xi), \xi\right) \geq \overline{P^{r 1}}\left(R(\bar{\xi}), p^{\prime}(\bar{\xi}), \xi\right), \\
\text { s.t. : } & (2) \overline{P^{r 1}}\left(R(\xi), p^{\prime}(\xi), \xi\right) \geq \overline{p_{\min }^{r 1}} .
\end{array}
$$

The goal function is to maximize the projected profit of the manufacturer. The purpose of constraint condition (1) is to limit the retailer's profit. The profit acquired under the condition of actual market demand information exceeds the profit received under the situation of misleading information. Constraint condition (2) is to carry out the retailer constraint's minimal return $\left(\overline{p_{\min }^{r 1}}\right)$. Its goal is to help retailers in providing accurate market demand information. To this, Yoon et al. [54] proposed two effective methods to induce retailers to give actual market demand information. It also shows that this effect depends on many factors, including the retailer's reliability and the cost of information sharing.

First, suppose

$$
\max \overline{P^{r 1}}\left(R(\bar{\xi}), p^{\prime}(\bar{\xi}), \xi\right)=\overline{P^{r 1}}(\xi) .
$$

Taking the partial derivative of $\xi$ in (18), we have

$$
\partial \overline{P^{r 1}} \frac{(\xi)}{\partial \xi}=\left(p-p^{\prime}\right) F(R(\bar{\xi})-d-v-\xi) \geq 0 .
$$

$\overline{P^{r 1}}(\xi)$ is about the increment function of $\xi$, and $\xi \in[a, b]$; when $\xi=a, \overline{P^{r 1}}(\xi)$ is the minimum, and then $p_{\min }^{r 1}=P^{r 1}\left(R(a), p^{\prime}(a), \xi\right)$. To sum up, the conclusions drawn based on the two constraints can ensure that the retailer will at least get the minimum profit given the authentic market demand information so that the retailer has the motivation to give it.

By the envelope principle available,

$$
\left.\frac{\mathrm{d} \overline{P^{r 1}}(\xi)}{\mathrm{d} \xi}\right|_{\bar{\xi}=\xi}=\left(p-p^{\prime}\right) F(R(\xi)-d-v-\xi) .
$$

Integrate both sides of the above formula, and substitute $\overline{p_{\text {min }}^{r 1}}$ into

$$
\overline{P^{r 1}}(\xi)=\frac{\mathrm{d} \overline{P^{r 1}}(\xi)}{\mathrm{d} \xi} \int_{a}^{\xi}\left(p-p^{\prime}\right) F(R(x)-d-v) \mathrm{d} x+\overline{p_{\min }^{r 1}} .
$$

Therefore, the manufacturer's profit can be expressed as

$$
E \overline{P^{m 1}} R(\xi), \quad p^{\prime}(\xi), \xi=\int_{a}^{b}\left[\overline{P^{s 1}}(R(\bar{\xi}), \xi)-\int_{a}^{\xi}\left(p-p^{\prime}\right) F(R(x)-d-v-x) \mathrm{d} x\right] g(\xi) \mathrm{d} \xi-\overline{p_{\min }^{r 1}} .
$$


According to the integral median theorem, the above formula can be expressed as

$$
E \overline{P^{m 1}}\left(R(\xi), p^{\prime}(\xi), \xi\right)=\int_{a}^{b}\left[\overline{P^{s 1}}(R(\bar{\xi}), \xi)-\left[\frac{1-G(\xi)}{g(\xi)}\right]\left(p-p^{\prime}\right)\right] F(R(\xi)-d-v-\xi) g(\xi) d \xi-\overline{p_{\min }^{r 1}}
$$

Among them, $[1-G(\xi) / g(\xi)]\left(p-p^{\prime}\right) F(R(\xi)-d-v-$ $\xi)$ is the profit loss caused by the manufacturer to reveal the retailer's authentic market demand information. In summary, the profit maximization problem for manufacturers should express as follows:

$$
L(R(\xi), \xi)=\overline{P^{s 1}}(R(\xi), \xi)-\left[\frac{1-G(\xi)}{g(\xi)}\right]\left(p-p^{\prime}\right) F(R(\xi)-d-v-\xi)
$$

Taking the first derivative of the above formula to make it zero can be obtained:

$$
(p-c)(1-F(R(\xi)-d-v-\xi))-C_{R}-\lambda-\left[\frac{1-G(\xi)}{g(\xi)}\right]\left(p-p^{\prime}\right) f(R(\xi)-d-v-\xi)=0 .
$$

According to this formula, the optimal response capability of the supply chain under asymmetric information can be obtained as $R_{s 3}$.

\subsection{Comparison of Responsiveness in Three Situations}

3.3.1. Compare $R_{s 1}$ and $R_{s 3}$. For all $\xi \in[a, b]$, when the retailer gives the real information $\xi, R_{s 1}$ is the optimal response ability of equation $(7)$, so $\overline{P^{s 1}}\left(R_{s 1}, \xi\right)>\overline{P^{s 1}}\left(R_{s 3}, \xi\right)$ and $R_{s 3}$ is the optimal solution of $L(R(\xi), \xi)$; then, the comparison equation of the above equation is substituted into equation (26) to obtain

$$
\left[\frac{1-G(\xi)}{g(\xi)}\right]\left(p-p^{\prime}\right)\left[F\left(R_{s 1}-d-v-\xi\right)-F\left(R_{s 3}-d-v-\xi\right)\right] \geq 0
$$

Because $F$ is an increasing function, $R_{s 1} \geq R_{s 3}$ is established; however, under asymmetric information of sudden market demand, the response ability is still not symmetrical information's optimal response ability, even though the manufacturer reveals the actual market demand.

3.3.2. Compare $R_{s 2}$ and $R_{s 3}$. Comparing $R_{s 2}$ and $R_{s 3}$ needs to be solved, where assuming that $\varepsilon$ and $\xi$ all obey the uniform distribution on $[a, b]$,

$$
\begin{aligned}
& R_{s 2}=0.5(a+3 b)+d+v+\frac{(a-b)\left(C_{R}+\lambda\right)}{p-c}, \\
& R_{s 3}=d+v+\frac{(a-b)\left(C_{R}+\lambda\right)+b\left(p^{\prime}-c\right)}{p-c}+\frac{\left(2 p-p^{\prime}-c\right)}{p-c} \xi .
\end{aligned}
$$

If $\quad R_{s 2}-R_{s 3} \leq 0, \quad$ then $\xi \geq b+(a-b)(c-p) / 2$ $\left(c-2 p+p^{\prime}\right)$ and $R_{s 3} \geq R_{s 2}$; this means when the manufacturer tempts the retailer to give the actual market demand information satisfying certain conditions, the response capacity of the supply chain under asymmetric information will be greater than the incomplete asymmetric information.

3.3.3. Compare $R_{s 1}$ and $R_{s 2}$. Same as above, assuming that $\varepsilon$ and $\xi$ all obey the uniform distribution on $[a, b]$,

$$
\begin{aligned}
& R_{s 1}=b+\xi+d+v+\frac{(a-b)\left(C_{R}+\lambda\right)}{p-c}, \\
& R_{s 2}=0.5(a+3 b)+d+v+\frac{(a-b)\left(C_{R}+\lambda\right)}{p-c} .
\end{aligned}
$$

Comparing the above two formulas, the difference between $R_{s 1}$ and $R_{s 2}$ may be seen in the value of $b+\xi-0.5(a+3 b)$; if $b+\xi-0.5(a+3 b) \geq 0$, then $R_{s 1} \geq R_{s 2}$; if $b+\xi-0.5(a+3 b)<0$, then $R_{s 1}<R_{s 2}$. 


\section{Case Analysis}

The article assumes that the supply chain is composed of manufacturers and retailers, and the responsiveness of the three situations mentioned above needs to be verified by substituting specific parameters. This article makes assumptions about the interval of independent variables based on the hypothesis principle of general mathematical models. This article's numerical assumptions are drawn from the apparel industry. The apparel industry's market price is frequently 2-3 times the ex-factory price (except for largebrand specialty stores). Then, assume that the values of each parameter

are

$p=30, p^{\prime}=15, C_{R}=3, c=5, d=40, v=35$, and $\lambda=1$, assuming that $\varepsilon$ and $\xi$ all obey the uniform distribution on $[-20,20]$; then, before the sudden demand, the profit of the supply chain is $P^{s}(R)=976.664$, the optimal response ability is $R^{*}=55.2$, and the response ability under the traditional wholesale price is $R^{\prime}=48, p^{\prime \prime}=1.8$, and $\tau=40 \%$.

The following will discuss the changes in the parameters of the supply chain's ability to respond to market demand after emergencies. To make it simpler to grasp how the data vary in different circumstances, this article rearranges the calculation results and presents them in Table 2. Table 2 shows the ideal values before the incident and the best values in each of the three information types thereafter. The reaction speed and profit ratio of the firm in each condition may be seen immediately from Table 2 .

(1) Figure 1 shows a change of the supply chain's profit and market demand response ability before and after the advent of sudden market demand under complete information symmetry. As can be seen, in emergency conditions, the profit and response capabilities of the supply chain with entirely symmetric information are higher than the optimal value under general conditions. Among them, $R_{s 1}=88.6+\xi>R^{*}=55.2, P^{s 1}\left(R_{s 1}\right)=1563+$ $21 \xi>P^{s}(R)=976.664$, and $\eta=30.84$ does not change. The manufacturer receives the 30.84 profit from the retailer.

(2) Under incomplete information symmetry, Figure 2 depicts the changes in the supply chain's profit and response ability before and after the emergency. $R_{s 2}=88.6, P^{s 1}\left(R_{s 2}\right)=1527.876$, and $R_{s 2}$ is a parameterless variable. The difference in response ability and profit between fully symmetric information and incompletely symmetric information is related to $\xi$, which can be found out by comparing $R_{s 1}$ and $R_{s 2}$. More importantly, the response ability and supply chain profit under the incomplete information symmetry are higher than the optimal values before the sudden demand. In conclusion, the emergency will benefit businesses by marketing and boost supply chain profit whether the information is totally symmetrical or incompletely symmetrical.

(3) Under information asymmetry, Figure 3 depicts the changes in the supply chain's profit and response ability before and after the emergency. Unlike completely symmetrical and incompletely symmetrical information, the former can directly expand the product under the same conditions, but only when $\xi \geq-13.375$ be satisfied, the information asymmetry's response ability will be better than the optimal values under normal circumstances, i.e., $R_{\mathrm{s} 3} \geq R^{*}$. At this time, the response ability is greater than the optimal value before the emergency, and the profit is still negative. Only when $\xi \geq-7.756$, the total profit of the supply chain under the information asymmetry will be higher than the normal situation. That is, only the increase in total profit will make the change of responsiveness meaningful.

Figure 4 depicts a comparison of the supply chain's responsiveness between the traditional and three information formats. Figure 5 compares the profit of the supply chain in traditional and three information formats. The following can be seen from Figures 4 and 5 .

First of all, Figure 4 shows that when $\xi<0, R_{s 2}>R_{s 1}>R^{*}$ occurs; when $\xi>0, R_{s 1}>R_{s 2}>R^{*}$ occurs. It means that emergency has a beneficial influence on the supply chain's response ability when information is complete and incompletely symmetrical. When $d$ is 15 , however, $F<c$. It indicates that an emergency can be positive or negative in a supply chain with asymmetric information. The degree of knowledge asymmetry in the supply chain will determine whether the outcome is favorable or unfavorable.

Second, point $a$ shows that the emergency management capabilities of enterprises with asymmetric information are relatively weak. In the event of an emergency, companies with asymmetric information will suffer losses first. In addition, when $\xi<0, R_{s 2}>R_{s 1}$; it shows that complete information symmetry is not necessarily optimal. The market transparency brought about by information sharing will reduce the total profit of the supply chain under certain conditions. It means companies should pay attention to the "degree" when advancing the process of information sharing. Under normal conditions, the gradual advancement of information sharing will benefit the development of enterprises. It can reduce some collateral damage when an emergency occurs.

Furthermore, point $C$ shows how asymmetric enterprises with more true market information might improve their capacity to respond to demand. When asymmetric information reaches point $C$, its reaction capacity is identical to that of asymmetric information. Information asymmetry will progressively approach complete information symmetry if it can continue to acquire genuine market information. Information asymmetry, on the contrary, is at its lowest point. So, asymmetric businesses are more likely to suffer losses in the case of an emergency. As a result, increasing information sharing has a favorable influence on corporate emergency management.

Why is information sharing not easy to develop further? This is because information sharing means increasing the 
TABLE 2: Values of various parameters in different states.

\begin{tabular}{|c|c|c|c|}
\hline \multirow[b]{2}{*}{$\begin{array}{l}\text { Before the } \\
\text { emergency }\end{array}$} & Optimal profit of the supply chain & $P^{s}(R)$ & 976.664 \\
\hline & $\begin{array}{c}\text { Optimal responsiveness of the supply } \\
\text { chain }\end{array}$ & $R^{*}$ & 55.2 \\
\hline \multirow{4}{*}{\multicolumn{2}{|c|}{$\begin{array}{l}\text { Responsiveness under the traditional wholesale model } \\
\text { Proportion of supply chain profit under production capacity } \\
\text { appointment }\end{array}$}} & $R^{\prime}$ & 38.67 \\
\hline & & Manufacturer: $\tau$ & $40 \%$ \\
\hline & & Retailer: $1-\tau$ & $60 \%$ \\
\hline & & Responsiveness: $R_{s 1}$ & $88.6+\xi$ \\
\hline & \multirow{4}{*}{ Information is completely symmetric } & Manufacturer: $\tau+\eta$ & $40 \%+30.84$ \\
\hline & & Retailer: $1-\tau-\eta$ & $60 \%-30.84$ \\
\hline & & Supply chain profit: $P^{s 1}\left(R_{s 1}\right)$ & $1563+21 \xi$ \\
\hline & & Responsiveness: $R_{s 2}$ & 88.6 \\
\hline \multirow[t]{5}{*}{ After an emergency } & Information is not completely & Manufacturer: $\tau+\eta$ & 641.9904 \\
\hline & symmetric & Retailer: $1-\tau-\eta$ & 885.8856 \\
\hline & & Supply chain profit: $P^{s 1}\left(R_{s 2}\right)$ & 1527.876 \\
\hline & & Responsiveness: $R_{s 3}$ & $76.6+1.6 \xi$ \\
\hline & Information asymmetry & $\begin{array}{c}\text { Supply chain profit: } P^{s 1}\left(R_{s 3}\right) \text { (loss of } \\
\text { profit) }\end{array}$ & $1267.1+35.825 \xi-0.026 \xi^{2}$ \\
\hline
\end{tabular}

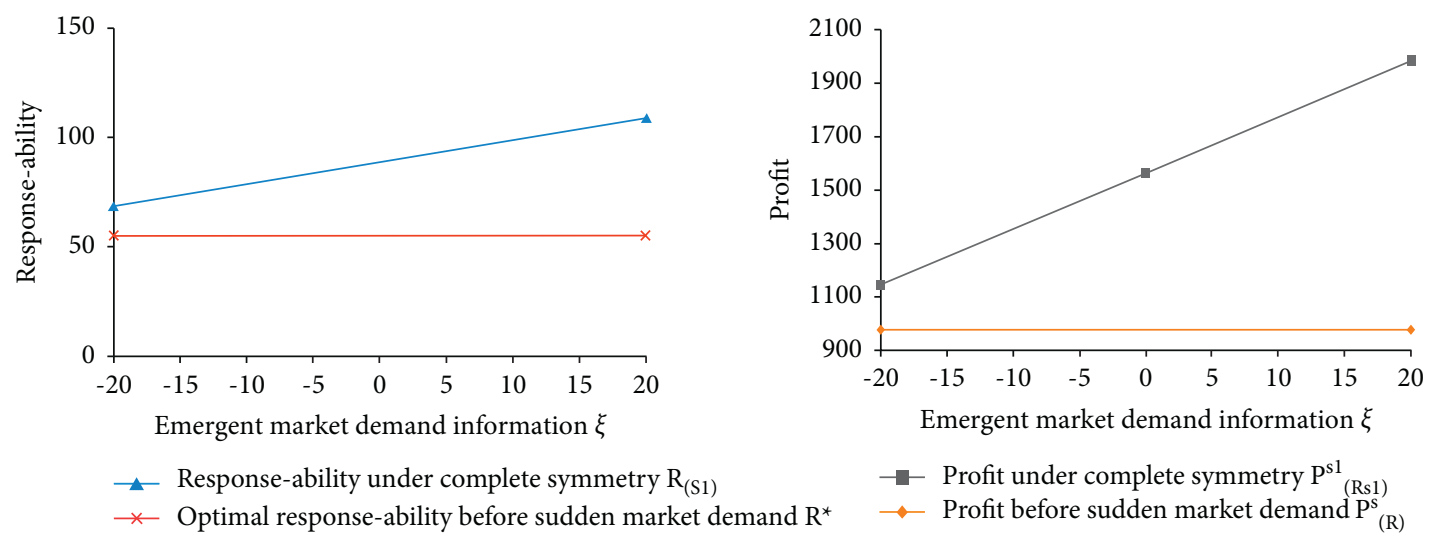

Figure 1: The change of supply chain's profit and response ability under completely symmetrical information before and after an emergency.

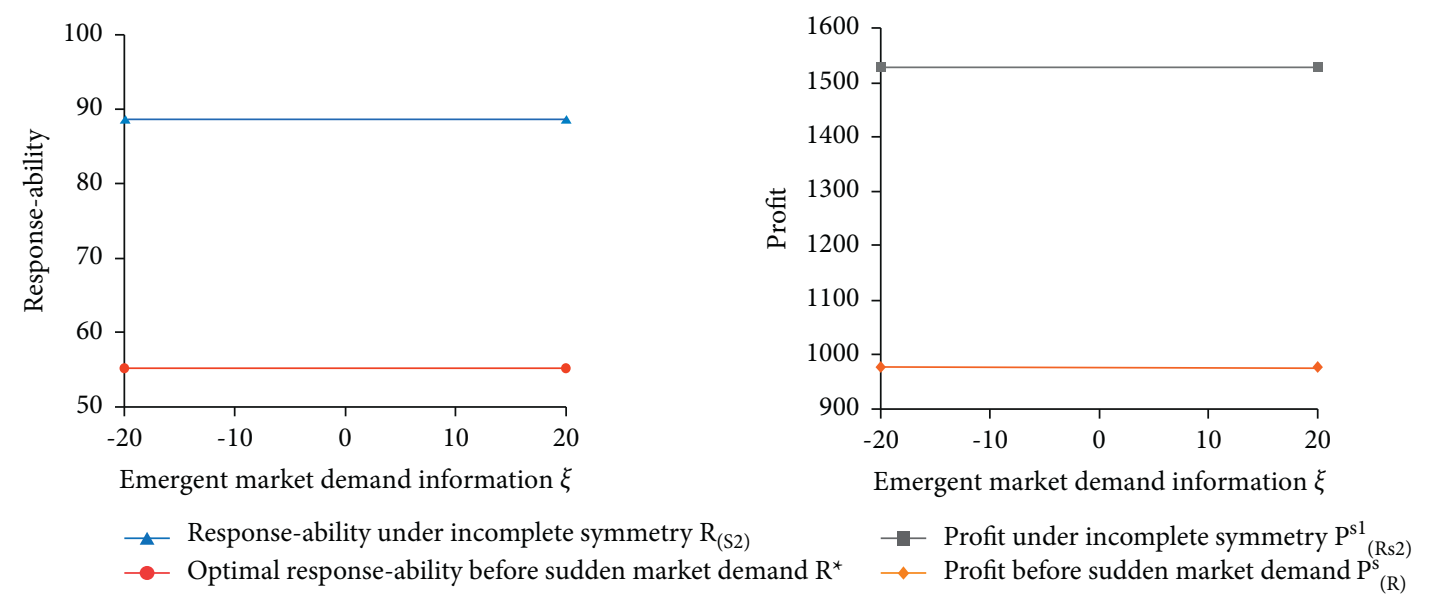

FIGURE 2: The change of supply chain's profit and response ability under incomplete symmetrical information before and after an emergency.

transparency of the supply chain, which will increase the difficulty and challenge for the survival of SMEs. Therefore, there are still SMEs that are reluctant to use cloud servers of large companies and insist on using their servers. Information sharing will indeed bring progress, but its realization needs to face too many difficulties. Among them, how to 

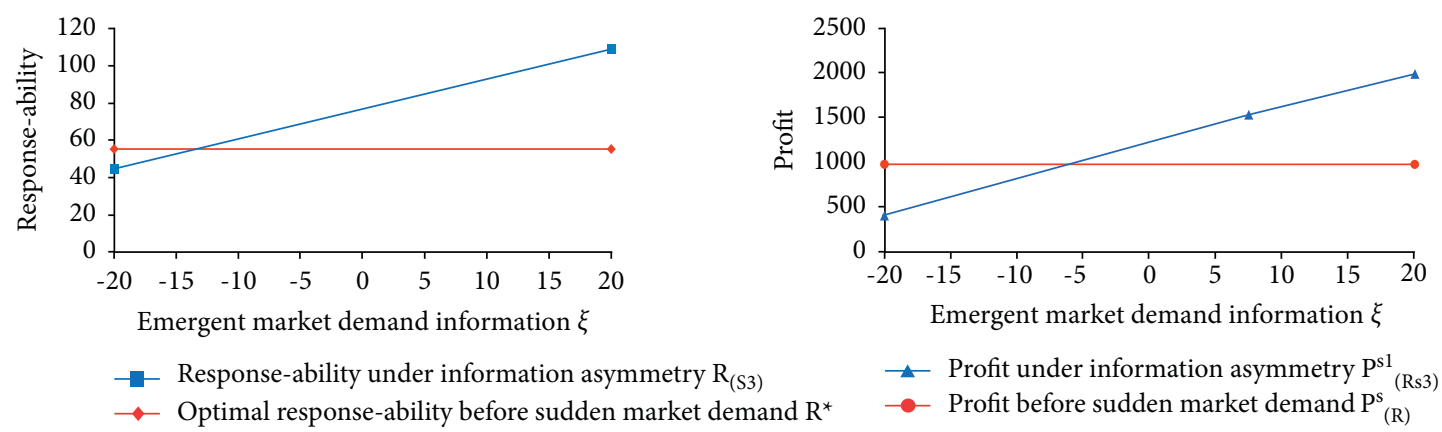

FIGURE 3: The change of supply chain's profit and response ability under asymmetric information before and after an emergency.

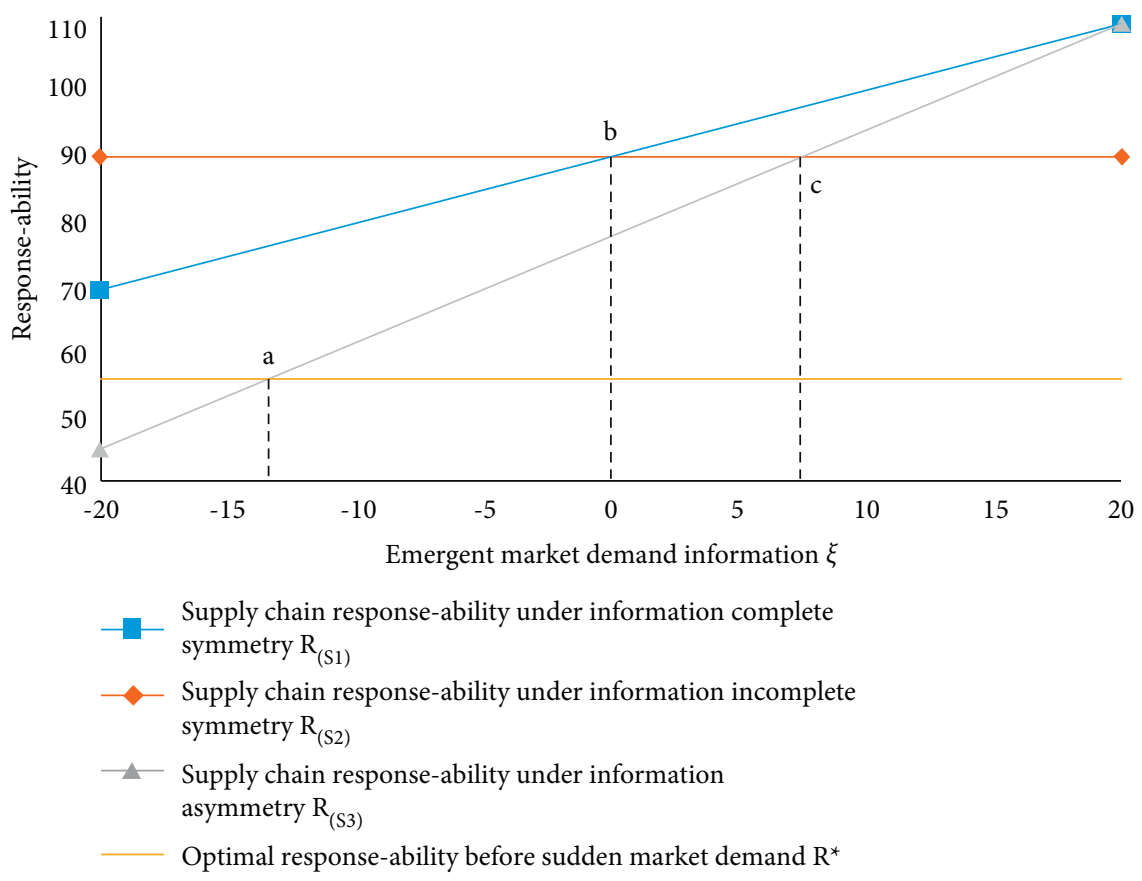

FIGURE 4: The changes of the response ability before and after an emergency.

reduce the loss caused by the lack of information sharing can be referred to in the literature by Shareef et al. [55], but supporters of supply chain information sharing emphasized potential benefits, such as improved distribution and utilization of logistics resources, improved production plans, reduced inventory costs, increased customer service, and shortened delivery times throughout the supply chain [56]. It also means the promotion of information sharing is of great significance for companies to improve their emergency management.

Finally, because the supply chain's responsiveness and profit are positively connected, the changes in Figure 5 are consistent with those of Figure 4. Point $F$ indicates that, under asymmetric information, the supply chain profits are losing. Point $B$ shows that while fully symmetric information is less responsive than incomplete symmetric information, the benefits of the two are already equal, indicating that fully symmetric information is in high emergency demand. Down has an advantage; point $G$ in Figure 4 has the same meaning as point $C$. More crucially, the area of triangle $C D E$ in Figure 5 illustrates the loss of knowledge asymmetry caused by a lack of information exchange across enterprises. It means that the responsiveness and profit of information asymmetry will be bigger than the responsiveness and profit under normal conditions only when the manufacturer's information disclosure level is high enough. In conclusion, boosting enterprise information sharing has a significant impact on improving supply chain profitability. 


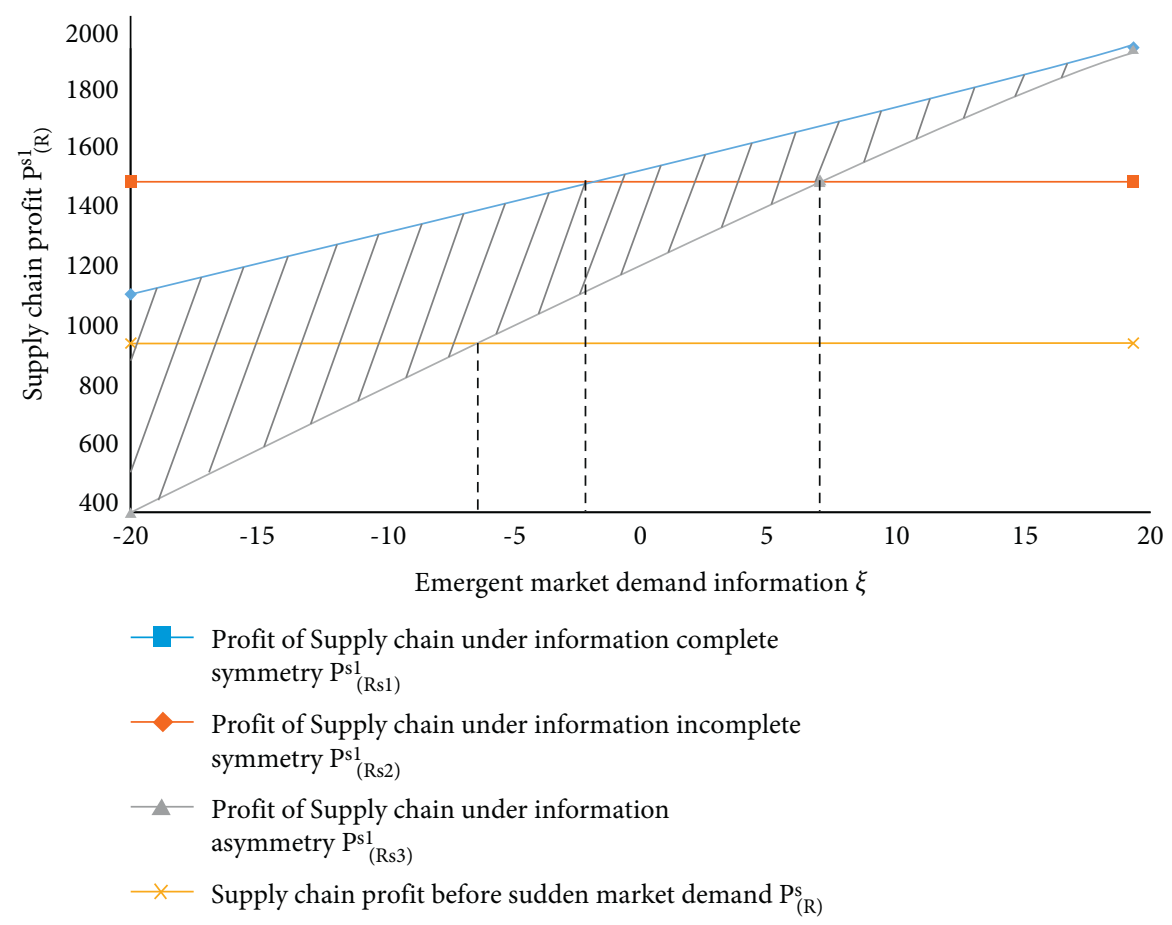

Figure 5: The changes of the profit before and after an emergency.

\section{Discussion and Conclusion}

Enterprises must be more flexible, respond swiftly to sudden market demand, meet consumer expectations, and improve the supply chain's emergency management capabilities to adapt to the sudden market demand created by frequent emergencies in recent years. The most direct indications of an enterprise's business status are responsiveness and economy. Furthermore, most businesses are undergoing digital transformation. Informatization is the same as so-called digitization. In this context, this paper examines the supply chain's emergency response capabilities and profits using three different information sharing methods in an emergency. The research presented in this article is critical for businesses looking for better emergency management through information sharing.

In an emergency, profit and responsiveness are nonlinear and positively correlated, according to the research. However, each information-sharing paradigm has its own set of benefits, so more information sharing is not necessarily better. Completely symmetrical information and incompletely symmetrical information have higher responsiveness and profit than the optimal value under typical situations. It is because information sharing can reduce the bullwhip effect/inventory costs. As a result, in this situation, businesses might improve their responsiveness and grow production. Enterprises with asymmetric information, on the contrary, acquire a large amount of genuine market information in an emergency because they need it to boost responsiveness and profit and prevent losses.

Establishing information sharing has a positive effect on improving the emergency management capabilities of enterprises. On the contrary, how can companies effectively build corporate information sharing? According to the findings of this study, it is necessary to transition from incomplete information symmetry to complete information symmetry to increase supply chain profits. Establishing incomplete information symmetry is more in line with the current digital transformation process and will not result in significant changes to the business. When the market demand caused by emergencies is low, it is more advantageous for the information to be incompletely symmetrical. The information-sharing mode needs to alter only when the market demand is big enough. Intuitively, it is the established route in Figure 5: $A \longrightarrow B \longrightarrow C$.

First, the distribution function employed in the model to depict market demand is regular, while actual market demand variations are far more intricate, particularly in an emergency. So, future studies should explore more perfect methods to replace the genuine market demand information. Second, the numerical numbers used in this article's calculation examples are only valid for a few industries. Because each industry's retail and wholesale pricing has different features, numerical illustration cannot encompass all industries. Finally, the research object of this article is only the two-level supply chain of manufacturers and retailers, but the actual supply chain situation is much more complicated, and a multilevel supply chain will be the direction of future research.

\section{Data Availability}

The data used to support the findings of this study are included within the article.

\section{Conflicts of Interest}

The authors declare that they have no conflicts of interest. 


\section{References}

[1] D. Jia and Z. Wu, "Intelligent evaluation system of government emergency management based on BP neural network," IEEE Access, vol. 8, pp. 199646-199653, 2020.

[2] S. Bhagavathula, K. Brundiers, M. Stauffacher, and B. Kay, "Fostering collaboration in city governments' sustainability, emergency management and resilience work through competency-based capacity building," International Journal of Disaster Risk Reduction, vol. 63, 2021.

[3] A. Zvikaramba, S. V. Kruglikov, T. Zimucha, and K. Sergei, "Disaster response supply chain in a city: the role of SMEs," International Journal of Supply Chain and Operations Resilience, vol. 4, no. 1, p. 85, 2020.

[4] S. Singh, R. Kumar, R. Panchal, and M. K. Tiwari, "Impact of COVID-19 on logistics systems and disruptions in food supply chain," International Journal of Production Research, vol. 59, no. 7, pp. 1993-2008, 2021.

[5] M. M. S. Sodhi and C. S. Tang, "Supply chain management for extreme conditions: research opportunities," Journal of Supply Chain Management, vol. 57, no. 1, pp. 7-16, 2021.

[6] S. Akter and S. F. Wamba, "Big data and disaster management: a systematic review and agenda for future research," Annals of Operations Research, vol. 283, no. 1, pp. 939-959, 2019.

[7] M. Balaji, S. N. Dinesh, P. M. Kumar, and K. Hari Ram, "Balanced Scorecard approach in deducing supply chain performance," Materials Today: Proceedings, vol. 47, 2021.

[8] P. Chand, J. J. Thakkar, and K. K. Ghosh, "Analysis of supply chain performance metrics for Indian mining \& earthmoving equipment manufacturing companies using hybrid MCDM model," Resources Policy, vol. 68, p. 101742, 2020.

[9] Y. Cao and H. Jiang, "Research on intelligent supply chain management under unconventional emergencies," EDP Sciences, vol. 235, p. 03015, 2021.

[10] J. Gerami, R. K. Mavi, R. F. Saen, and N. K. Mavi, “A novel network DEA-R model for evaluating hospital services supply chain performance," Annals of Operations Research, no. 1, 2020.

[11] Y. He, X. D. Liang, F. M. Deng, and Z. Li, "Emergency supply chain management based on rough set-house of quality," International Journal of Automation and Computing, vol. 16, no. 3, pp. 297-309, 2019.

[12] T. G. Hawkins, M. J. Gravier, and W. A. Muir, "The role of supplier performance evaluations in mitigating risk: assessing evaluation processes and behaviors," Industrial Marketing Management, vol. 87, 2020.

[13] A. Chen, N. Chen, and J. Li, "During-incident process assessment in emergency management: concept and strategy," Safety Science, vol. 50, no. 1, pp. 90-102, 2012.

[14] C. Owen, B. Brooks, C. Bearman, and S. Curnin, "Values and complexities in assessing strategic-level emergency management effectiveness," Journal of Contingencies and Crisis Management, vol. 24, no. 3, pp. 181-190, 2016.

[15] M. Tavana, "Dynamic process modelling using Petri nets with applications to nuclear power plant emergency management," International Journal of Simulation and Process Modelling, vol. 4, no. 2, pp. 130-138, 2008.

[16] D. Chen, Y. Sun, and J. Li, "Construction of evaluation index system for emergency rescue capacity of rail transit under serious epidemic situation," Journal of Traffic and Transportation Engineering, vol. 20, no. 3, pp. 129-138, 2020.

[17] A. Larsson, L. Ekenberg, and M. Danielson, "Decision evaluation of response strategies in emergency management using imprecise assessments," Journal of Homeland Security and Emergency Management, vol. 7, no. 1, 2010.

[18] S. Oh, H. C. Moon, and Y. Zhong, "Contingency management and supply chain performance in korea: a COVID-19 pandemic approach," Sustainability, vol. 12, 2020.

[19] S. Agarwal, R. Kant, and R. Shankar, "Evaluating solutions to overcome humanitarian supply chain management barriers: a hybrid fuzzy SWARA-Fuzzy WASPAS approach," International Journal of Disaster Risk Reduction, vol. 51, p. 101838, 2020.

[20] H. I. Asala, J. A. Chebeir, V. Manee, and I. Gupta, "An integrated machine-learning approach to shale-gas supplychain optimization and refrac candidate identification," $S P E$ Reservoir Evaluation and Engineering, vol. 22, no. 4, 2019.

[21] A. Mohammed, "Towards a sustainable assessment of suppliers: an integrated fuzzy TOPSIS-possibilistic multi-objective approach," Annals of Operations Research, vol. 293, 2020.

[22] J. Wang, B. Yuan, Z. Li, and Z. Wang, "Evaluation of public health emergency management in China: a systematic review," International Journal of Environmental Research and Public Health, vol. 16, no. 18, p. 3478, 2019.

[23] D. Huang, S. Wang, and Z. Liu, "A systematic review of prediction methods for emergency management," International Journal of Disaster Risk Reduction, vol. 62, Article ID 102412, 2021.

[24] Y. X. Chen and Y. Song, "Emergency response capability assessment of emergency supply chain coordination mechanism based on hesitant fuzzy information," International Journal of Simulation Modelling, vol. 13, no. 4, pp. 485-496, 2014.

[25] X. Zhou, Y. Shi, X. Deng, and Y. Deng, "D-DEMATEL: a new method to identify critical success factors in emergency management," Safety Science, vol. 91, pp. 93-104, 2017.

[26] X. Liu, Z. Wang, S. Zhang, and J. Liu, "Analysis of influencing factors in emergency management based on an integrated methodology," Adaptive Behavior, vol. 27, no. 5, pp. 331-345, 2019.

[27] Y. Li, Y. Hu, X. Zhang, and S. Mahadevan, "An evidential DEMATEL method to identify critical success factors in emergency management," Applied Soft Computing, vol. 22, pp. 504-510, 2014.

[28] X. F. Ding and H. C. Liu, "A 2-dimension uncertain linguistic DEMATEL method for identifying critical success factors in emergency management," Applied Soft Computing, vol. 71, pp. 386-395, 2018.

[29] S. Sahinoz, U. Yaprak, and T. Sahinoz, "Employees' opinions on critical success factors and performance criteria in disaster and emergency management," Pakistan journal of medical sciences, vol. 35, no. 6, p. 1636, 2019.

[30] Y. Cao and J. He, "Research on emergency logistics management based on Intelligent supply chain," E3S Web of Conferences, vol. 235, no. 4, 2021.

[31] Y. Liu, Z. Fan, and H. Qi, "Dynamic statistical evaluation of safety emergency management in coal enterprises based on neural network algorithms," Journal of Intelligent and Fuzzy Systems, vol. 39, no. Preprint, pp. 1-14, 2020.

[32] S. M. Mochalin and V. A. Radionova, "Impact assessment of the supply chain based on the theory of fuzzy sets," Journal of Physics: Conference Series, vol. 1901, no. 1, p. 012040, 2021.

[33] S. Shan, X. Liu, Y. Wei, L. Xu, B. Zhang, and L. Yu, "A new emergency management dynamic value assessment model based on social media data: a multiphase decision-making perspective," Enterprise Information Systems, vol. 14, no. 5, pp. 680-709, 2020. 
[34] X. Ge, J. Yang, H. Wang, and S. Wanqing, "A fuzzy-TOPSIS approach to enhance emergency logistics supply chain resilience," Journal of Intelligent and Fuzzy Systems, vol. 38, no. 6, pp. 6991-6999, 2020.

[35] L. N. K. Duong and J. Chong, "Supply chain collaboration in the presence of disruptions: a literature review," International Journal of Production Research, vol. 58, no. 11, pp. 3488-3507, 2020.

[36] J. Oliveira, "The balanced scorecard: an integrative approach to performance evaluation," Healthcare Financial Management, vol. 55, no. 5, p. 42, 2001.

[37] J. Zhang and S. Fu, "Performance evaluation of emergency logistics based on DEA-AHP algorithm," Journal of the ICE, vol. 3, pp. 527-532, 2011.

[38] F. Deng, X. Zhang, X. Liang, Z. Guo, and C. Bao, "Earthquake disaster emergency supply chain performance evaluation based on triangular fuzzy numbers," in Proceedings of the 2016 IEEE International Conference on Industrial Engineering and Engineering Management (IEEM), pp. 1483-1487, IEEE, Bali, Indonesia, December 2016.

[39] H. R. C. G. L. Bangwang, "Performance evaluation for emergency logistic outsourcing vendor based on fussy analytical hierarchical process," Journal of Southeast University (Natural Science Edition), p. S2, 2007.

[40] G. F. Zhang, L. H. He, and S. Li, "A fuzzy-random optimization approach using fuzzy measure and fuzzy integral for emergency risk coordination of supply chain," in Proceedings of the 2014 International Conference on Machine Learning and Cybernetics, pp. 789-795, Lanzhou, China, July 2014.

[41] Y. Zhang, W. G. Weng, and Z. L. Huang, "A scenario-based model for earthquake emergency management effectiveness evaluation," Technological Forecasting and Social Change, vol. 128, pp. 197-207, 2018.

[42] Y. Zhang, Q. Ding, and J. B. Liu, "Performance evaluation of emergency logistics capability for public health emergencies: perspective of COVID-19," International Journal of Logistics Research and Applications, pp. 1-14, 2021.

[43] S. Bingzhen and M. Weimin, "An approach to evaluation of emergency plans for unconventional emergency events based on soft fuzzy rough set," Kybernetes, vol. 45, no. 3, 2016.

[44] M. Raweewan and W. G. Ferrell, "Information sharing in supply chain collaboration," Computers \& Industrial Engineering, vol. 126, pp. 269-281, 2018.

[45] T. Clauss and C. Tangpong, "Perception-based supplier attributes and performance implications: a multimethod exploratory study," Journal of Supply Chain Management, vol. 55, no. 4, 2019.

[46] I. C. Wang, "To construct a cost reduction model by information sharing in a supply chain," Applied Science and Management Research, vol. 6, no. 1, pp. 43-53, 2019.

[47] M. Sufiyan, A. Haleem, S. Khan, and M. I. Khan, "Evaluating food supply chain performance using hybrid fuzzy MCDM technique," Sustainable Production and Consumption, vol. 20, pp. 40-57, 2019.

[48] R. H. Teunter, M. Z. Babai, J. A. C. Bokhorst, and A. A. Syntetos, "Revisiting the value of information sharing in two-stage supply chains," European Journal of Operational Research, vol. 270, no. 3, pp. 1044-1052, 2018.

[49] S. Torpan, S. Hansson, M. Rhinard et al., "Handling false information in emergency management: a cross-national comparative study of European practices," International Journal of Disaster Risk Reduction, vol. 57, no. 2, p. 102151, 2021.

[50] A. Y. Ha, Q. Tian, and S. Tong, "Information sharing in competing supply chains with production cost reduction,"
Manufacturing \& Service Operations Management, vol. 19, no. 2, pp. 246-262, 2017.

[51] G. Li, H. Zheng, S. P. Sethi, and X. Guan, "Inducing downstream information sharing via manufacturer information acquisition and retailer subsidy," Decision Sciences, vol. 51, no. 3, pp. 691-719, 2020.

[52] J. Liao, "Review of research on performance evaluation of supply chain business process," Logistics Technology, vol. 38, no. 2, pp. 88-93, 2019.

[53] F. R. Lima-Junior and L. C. R. Carpinetti, "Quantitative models for supply chain performance evaluation: a literature review," Computers \& Industrial Engineering, vol. 113, pp. 333-346, 2017.

[54] J. Yoon, S. Talluri, and C. Rosales, "Procurement decisions and information sharing under multi-tier disruption risk in a supply chain," International Journal of Production Research, vol. 58, no. 5, pp. 1362-1383, 2020.

[55] M. A. Shareef, Y. K. Dwivedi, V. Kumar, D. Laurie Hughes, and R. Raman, "Sustainable supply chain for disaster management: structural dynamics and disruptive risks," Annals of Operations Research, pp. 1-25, 2020.

[56] J. Kembro, D. Näslund, and J. Olhager, "Information sharing across multiple supply chain tiers: a Delphi study on antecedents," International Journal of Production Economics, vol. 193, pp. 77-86, 2017. 